Check for updates

Cite this: RSC Adv., 2018, 8, 724

Received 27th September 2017 Accepted 18th December 2017

DOI: 10.1039/c7ra10695e

rsc.li/rsc-advances

\section{Mechanism and effect of $\gamma$-butyrolactone solvent vapor post-annealing on the performance of a mesoporous perovskite solar cell}

\author{
Jun Luo, ${ }^{a}$ Ren Zheng Qiu, ${ }^{a}$ Zhi Sheng Yang, ${ }^{a}$ Yan Xiang Wang (iD *a \\ and Qi Feng Zhang*b
}

In this paper, $\gamma$-butyrolactone (GBL) solvent vapor post-annealing (SVPA) on $\mathrm{CH}_{3} \mathrm{NH}_{3} \mathrm{Pbl}_{3}$ thin films is reported, aiming to improve the complete transformation of $\mathrm{Pbl}_{2}$ and increase the grain size of the $\mathrm{CH}_{3} \mathrm{NH}_{3} \mathrm{Pbl}_{3}$ crystal, thus boosting the performance of mesoporous $\mathrm{CH}_{3} \mathrm{NH}_{3} \mathrm{Pbl}_{3}$ perovskite solar cells (PSCs). The influence of GBL SVPA on the microstructure of perovskite layers and performance of PSCS was studied. The short circuit current density $\left(J_{s c}\right)$ of the devices significantly increased, yielding a high efficiency of $16.58 \%$, which was $27.05 \%$ higher than that of thermally annealed films. A model was derived to explain the effect of GBL SVPA on PSCs. The perovskite films prepared by this method present several advantages such as complete transformation of $\mathrm{Pbl}_{2}$ to $\mathrm{CH}_{3} \mathrm{NH}_{3} \mathrm{Pbl}_{3}$, high crystallinity, large grain size, and fewer grain boundaries than those prepared without GBL SVPA. This improvement is beneficial for charge dissociation and transport in hybrid photovoltaic devices.

\section{Introduction}

In recent years, organometal halide perovskite solar cells (PSCs), which are considered to be the most promising nextgeneration solar cells, have been extensively investigated. ${ }^{1,2}$ In addition to their intense broadband absorption, ${ }^{3}$ this type of PSC also possesses small exciton binding energies (around $50 \mathrm{meV}$ at room temperature), ${ }^{4,5}$ long charge carrier diffusion lengths $(100-1000 \mathrm{~nm})$ and lifetimes $(\sim 100 \mathrm{~ns}),{ }^{6}$ good ambipolar charge mobilities, and low cost. ${ }^{7}$ PSCs have attracted worldwide attention due to these merits. Moreover, organometal halide perovskite materials can be solution-processed at low temperatures. With the development of organometal halide PSCs, the power conversion efficiency (PCE) of PSCs has increased from $3.8 \%{ }^{8}$ to $>21 \% .^{9}$

As a polycrystalline thin film, the optoelectronic properties of perovskite films and device performance highly depend on morphology such as crystallinity and grain size. ${ }^{10}$ The groups of Huang and Mohite have respectively demonstrated that the diffusion length and carrier mobility can be significantly improved in large grained perovskite films (over $3 \mu \mathrm{m}$ ). ${ }^{11-13}$ This suggests that ideal perovskite films for solar cells should consist of grains as large as possible. However, solution-processed perovskite films usually have relatively small grain sizes (within a couple of hundred nanometers $(\mathrm{nm})$ ) due to the quick reaction

${ }^{a}$ School of Materials Science and Engineering, Jingdezhen Ceramic Institute, Jingdezhen 333403, China. E-mail: yxwang72@163.com

${ }^{b}$ Department of Electrical and Computer Engineering, North Dakota State University, Fargo, ND, 58108, USA. E-mail: qifeng.zhang@ndsu.edu of lead iodide $\left(\mathrm{PbI}_{2}\right)$ and methyl-ammonium iodide (MAI), and the quick crystallization of these perovskite materials $\left(\mathrm{MAPbI}_{3}\right)$. The small grain size of $\mathrm{MAPbI}_{3}$ has more grain boundaries, which increases charge recombination and results in a decrease in PCE. A great deal of efforts have been made to control the morphology (larger grain size and better crystallinity) of the perovskite films by varying precursor concentrations ${ }^{14,15}$ or ratios, ${ }^{16,17}$ adjusting. the annealing conditions, ${ }^{18,19}$ and using additives. ${ }^{20-22}$ The solvent or vapor assisted process is an effective method to optimize the quality of perovskite films. ${ }^{14,23-29}$ Solvents such as $N, N$-dimethylformamide (DMF) have been successfully applied in solventassisted processes. ${ }^{23,30}$ Introducing DMF vapor during the annealing process provides the wet environment for the precursor ions and molecules to diffuse a long distance, resulting in growth of large sized grains. In addition to the dissolving solvent, dropping a non-dissolving solvent (such as toluene, diethyl ether, etc.) into a perovskite precursor film during the spin coating process has also been used to produce highly crystalline uniform perovskite films..$^{14,17,31}$

The selected non-dissolving solvent, which does not dissolve the perovskite materials and is miscible with other solvents (added to dissolve $\mathrm{PbI}_{2}$ and MAI), is dripped on the substrate where the perovskite is deposited during spin-coating. Subsequently, a stable intermediate phase is formed via an intercalation process during the drop-wise application of a nondissolving solvent. It is a decisive factor in retarding the rapid reaction between MAI and $\mathrm{PbI}_{2}$, which enables the formation of a highly uniform and dense film. Eventually, perovskite can be obtained after thermal annealing. However, these methods are difficult to control accurately. 
The perovskite film will be eroded if excessive solvent is added. Similarly, the homogeneous perovskite film will not be obtained if the non-dissolving solvent is not dropped at the accurate time. ${ }^{31}$ In addition, it has been difficult to extend these operations to large area production. Therefore, exploring a simple and effective method to produce high quality perovskite films is required.

The solvent vapor post-annealing (SVPA) process is different from the solvent- or vapor-assisted process. The SVPA process involves heating the prepared perovskite films in some solvent vapor for a specific time. ${ }^{32,33}$ The SVPA process has been widely used to fabricate organic thin films and solar cells to control the morphology. ${ }^{34,35}$ During the SVPA process, solvent molecules are absorbed in the thin films. The absorbed solvent may decrease the diffusive energy barrier and promote the rearrangements of grains, ${ }^{34}$ which will improve the crystallinity and carrier mobility of the perovskite films. In 2014, Huang first reported that the SVPA process is an effective method to increase the grain size and carrier diffusion lengths of trihalide perovskite materials. ${ }^{33}$ They found that the average grain size of the $\mathrm{CH}_{3}$ $\mathrm{NH}_{3} \mathrm{PbI}_{3}$ films after the SVPA process increased to $1 \mu \mathrm{m}$, which was comparable to the film thickness, while the maximum grain size in thermally annealed films was only around $260 \mathrm{~nm}$. In 2015, Liu systematically studied the influence of different SVPA atmospheres on perovskite films including $\mathrm{N}_{2}, \mathrm{H}_{2} \mathrm{O}$, DMF, $\gamma$ butyrolactone (GBL), and dimethyl sulfoxide (DMSO). They found that DMSO was the best solvent. ${ }^{32}$ Fang et al. reported high quality $\mathrm{CH}_{3} \mathrm{NH}_{3} \mathrm{PbI}_{3-x} \mathrm{Cl}_{x}$ perovskite films using chlorobenzene (CB) vapor post-annealing. ${ }^{36}$ They found that this method had a positive effect on the interfacial contact between the perovskite film and the upper PCBM film. Hybrid PSCs with planar heterojunctions fabricated by this method demonstrated a reproducible optimal PCE of $14.79 \%$ and an average PCE of $13.40 \%$, which were better than those when thermally annealed.

Compared with the prevailing anti-solvent dripping method-which needs precise control of the dripping timingSVPA is more compatible and reproducible for preparing largearea and high-quality perovskite thin films, opening up opportunities for the development of high performance perovskite solar cells and other optoelectronic devices.

To the best of our knowledge, there are very few articles reporting the SVPA of perovskite films. Only a few solvents were used such as phenyltrichlorosilane (PTS), octadecyltrichlorosilane (OTS), ${ }^{37}$ water, ${ }^{38}$ alcohol, ${ }^{39}$ dimethylsulfoxide (DMSO), ${ }^{40}$ and DMF. ${ }^{41-45}$ The most commonly used solvents are DMSO and DMF. It is easy to form coordination complexes, accompanied by volume expansion when using DMSO or DMF as solvent for vapor post-annealing to prepare perovskite films. ${ }^{17,46}$ Moreover, residual DMSO or DMF may form pinholes and destroy the perovskite layer causing volume shrinkage. Moreover, only a few articles demonstrated the morphology and performance analysis of the corresponding photovoltaic devices with and without SVPA. There are no other related reports on the mechanism and effect of SVPA on the morphological characteristics and revolutions of the perovskite films. A detailed study is helpful to break the bottleneck and obtain better performances in large grain PSCs.
GBL is a low solubility solvent for $\mathrm{CH}_{3} \mathrm{NH}_{3} \mathrm{PbI}_{3}$. It is difficult to form coordination complexes in GBL solution while single crystals of perovskite can be formed in GBL solution. ${ }^{47}$ When the temperature of GBL solution is near $60^{\circ} \mathrm{C}$, the solubility of $\mathrm{CH}_{3} \mathrm{NH}_{3} \mathrm{PbI}_{3}$ is highest. This indicates that the GBL solution is a good candidate for SVPA to obtain high quality perovskite films at low temperature, which will reduce the cost and be suitable for flexible thin-film solar cells.

Inspired by existing related studies, we adopted GBL for postannealing treatment of perovskite films. In this study, we investigated the effect of GBL solvent vapor post-annealing on the characteristics of perovskite films and performances of the corresponding PSCs. Moreover, we proposed the mechanism of GBL SVPA. We found that larger grain size, better crystallinity and complete reaction of $\mathrm{PbI}_{2}$ with MAI are the main factors that led to improved photoelectric performance. Eventually, PCE of $16.58 \%$ was achieved.

\section{Experimental section}

\section{Materials}

Methylammonium iodide $\left(\mathrm{CH}_{3} \mathrm{NH}_{3} \mathrm{I}, 99.8 \%\right.$, Dyesol), lead iodide $\left(\mathrm{PbI}_{2}, 99.999 \%\right.$, Sigma), $N, N$-dimethylformamide (DMF, 99.9\%, Aladdin), dimethyl sulfoxide (DMSO, 99.9\%, Aladdin), chlorobenzene (99.9\%, Aladdin), 1-butanol (99.6\%, Aladdin), lithium bis(trifluoromethanesulfonyl)imide (Li-TFSI, 99\%, Aladdin), $\gamma$-butyrolactone (GBL, 99\%, Aladdin), isopropanol (99.7\%, Sinopharm Chemical Reagent Co., Ltd), titanium diisopropoxide bis(acetylacetonate) (75 wt\% in isopropanol, Sigma Aldrich), $\mathrm{TiCl}_{4}$ (>98\%, Sigma Aldrich), and spiro-MeOTAD $(>99.5 \%$, Lumtec) were used as hole receptor without further purification.

\section{Perovskite film and solar cell fabrication}

F-doped $\mathrm{SnO}_{2}$ (FTO, NSG, TEC A7) substrates were cleaned with a sequence of detergent, deionized water, acetone, and isopropanol for $15 \mathrm{~min}$ in an ultrasonic bath. The precleaned FTO substrates were dried under a nitrogen stream and subjected to ultraviolet ozone treatment for $20 \mathrm{~min}$.

The $\mathrm{TiO}_{2}$ blocking layer (BL) was spin-coated on the FTO substrate at $2000 \mathrm{rpm}$ for $30 \mathrm{~s}$ using a solution of $0.15 \mathrm{M}$ titanium diisopropoxide bis(acetylacetonate) in 1-butanol, which was heated at $135{ }^{\circ} \mathrm{C}$ for $10 \mathrm{~min}$. After cooling to room temperature, the spin-coating process was repeated to obtain a $\mathrm{TiO}_{2} \mathrm{BL}$ with proper thickness. A mesoporous $\mathrm{TiO}_{2}$ layer composed of $20 \mathrm{~nm}$ nanoparticles was then prepared by spincoating at $5000 \mathrm{rpm}$ for $30 \mathrm{~s}$ using a commercial $\mathrm{TiO}_{2}$ paste (Dyesol 18NRT, Dyesol) diluted in ethanol (2:7 mass ratio weight ratio). The as-deposited $\mathrm{TiO}_{2}$ films were dried at $135{ }^{\circ} \mathrm{C}$ for $10 \mathrm{~min}$, gradually heated to $500{ }^{\circ} \mathrm{C}$ in air, and finally baked at this temperature for $30 \mathrm{~min}$ to remove organic components. The electrodes were soaked in $40 \mathrm{mM} \mathrm{TiCl}{ }_{4}$ aqueous solution at $70{ }^{\circ} \mathrm{C}$ for $30 \mathrm{~min}$ and then rinsed with deionized water followed by annealing at $500{ }^{\circ} \mathrm{C}$ for another $30 \mathrm{~min}$. Finally, the films were subjected to UV/ozone treatment for $15 \mathrm{~min}$. 

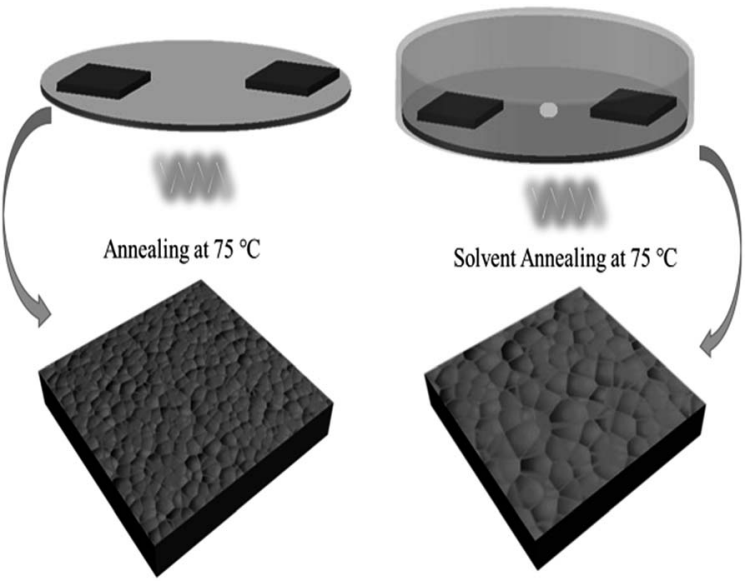

Scheme 1 Schematic illustration of GBL-vapor solvent post-annealing process.

$\mathrm{PbI}_{2}$ solution was prepared by dissolving $462 \mathrm{mg} \mathrm{PbI}_{2}$ in a mixed solvent of $74 \mu \mathrm{L}$ DMSO and $700 \mu \mathrm{L}$ DMF while stirring at $60{ }^{\circ} \mathrm{C}$. Prior to spin-coating of $\mathrm{PbI}_{2}$, the $\mathrm{PbI}_{2}$ solution and mesoporous $\mathrm{TiO}_{2}$ thin film were heated at $105{ }^{\circ} \mathrm{C}$. The $\mathrm{PbI}_{2}$ solution $(80 \mu \mathrm{L})$ was spin-coated on the mesoporous $\mathrm{TiO}_{2}$ film at $5000 \mathrm{rpm}$ for $30 \mathrm{~s}$ and $300 \mu \mathrm{L}$ chlorobenzene was spin-coated again. After spinning, the film was immersed into MAI solution (10 $\mathrm{mg} \mathrm{mL}^{-1}$ in isopropanol) for $10 \mathrm{~min}$. The corresponding thin film was spin-coated at $3000 \mathrm{rpm}$ again to dry the film. Finally, the complex film was annealed at $105{ }^{\circ} \mathrm{C}$ for $10 \mathrm{~min}$ in ambient air (relative humidity $40 \%$ at $25{ }^{\circ} \mathrm{C}$ ).

For the film treated with SVPA, the perovskite films were put on a hotplate, covered with a Petri dish, and annealed at $75{ }^{\circ} \mathrm{C}$ for about $30 \mathrm{~min}$. GBL solvent $(10 \mu \mathrm{L})$ was dropped at the center of the Petri dish so that GBL vapor could enter the Petri dish and form the GBL vapor atmosphere. The processing scheme for perovskite thin film formation using solvent vapor postannealing methods is shown in Scheme 1. The stacking films were then annealed at $100{ }^{\circ} \mathrm{C}$ with or without GBL vapor for $1 \mathrm{~h}$. The films without solvent annealing only went through thermal annealing and were used as control samples.

After annealing treatment with GBL solvent, a volume of $80 \mu \mathrm{L}$ of $2,2^{\prime}, 7,7^{\prime}$-tetrakis( $N, N$-di-p-methoxyphenylamine)-9,9-spirobifluorene (spiro-MeOTAD) solution was spin-coated on the $\mathrm{CH}_{3}$ $\mathrm{NH}_{3} \mathrm{PbI}_{3}$ perovskite layer at $3000 \mathrm{rpm}$ for $30 \mathrm{~s}$. The spiro-MeOTAD solution was prepared by dissolving $72.3 \mathrm{mg}$ of spiro-MeOTAD in $1 \mathrm{~mL}$ of chlorobenzene, to which $28.8 \mu \mathrm{L}$ of 4 -tert-butyl pyridine and $17.5 \mu \mathrm{L}$ of lithium bis(trifluoromethanesulfonyl)imide (Li-TFSI) solution $\left(520 \mathrm{mg} \mathrm{mL}^{-1}\right.$ in acetonitrile) were added. Finally, $80 \mathrm{~nm}$ thick gold was thermally evaporated on top of the device to form the back contact. The active area was fixed to $0.1 \mathrm{~cm}^{2}$ using a black mask.

\section{Characterization}

The crystal structures of the samples were characterized using an X-ray diffraction (XRD) system (Bruker D8 Advance) with Cu$\mathrm{K}_{\alpha}(1.5406 \AA)$. The morphologies of the samples were investigated by scanning electron microscopy (SEM, Hitachi S-4800).
The energy conversion efficiencies of solar cells were evaluated under AM1.5 (100 $\mathrm{mW} \mathrm{cm}^{-2}$ ) simulated sunlight (Newport, Serial 382, LampSBF178, Model 94023A). A power source meter (Keithley 2400) was used to measure the response of the solar cells. Incident photo-to-current conversion efficiencies (IPCE) of PSCs were measured by a solar cell quantum efficiency measurement system (Newport, $150 \mathrm{~W}$ xenon lamp, with a CS260-USB-Q-MC-A monochromator and 2936-R power meter). Ultraviolet-visible absorption spectra were recorded on a spectrophotometer (PerkinElmer, Lambda 850) in the 400$1100 \mathrm{~nm}$ wavelength range at room temperature. All measurements of the solar cells were performed under ambient atmosphere at room temperature.

\section{Results and discussion}

\section{Characterization of perovskite layer}

The influences of GBL SVPA on the morphology and crystal structure of the perovskite films were examined by SEM and XRD. Fig. 1 shows SEM images of perovskite films. The thermally annealed perovskite film exhibits smaller crystals and possesses many crystal boundaries (Fig. 1a). These boundaries will be trapping centers for exciton recombination and will reduce the $J_{\mathrm{sc}}$ and the PCE of the photovoltaic devices. In contrast, when GBL SVPA is introduced, the as-prepared perovskite films in Fig. 1b possess large crystallites and low densities of crystal boundaries, resulting in a surface morphology with higher homogeneity. Their in-plane grain size distributions charts were drawn using Image-Pro-Plus software (Fig. 2). The in-plane grain sizes of the perovskite layers without and with SVPA were $193 \mathrm{~nm}$ and $235 \mathrm{~nm}$, respectively. In addition, cross-sectional SEM images of these devices (Fig. 1c and d) imply that the grains along the thickness of the device in the GBL SVPA perovskite film are also larger than those of the thermally annealed device. Fig. 1d shows that the grains of the GBL SVPA perovskite film penetrate the entire capping layer. Thus, there is no need to cross any grain boundary when the carriers are transported to the electrode, which greatly enhances the charge extraction process and reduces recombination to improve solar cell performance. In comparison, the photogenerated charges of the perovskite film without SVPA have to cross several grain boundaries during their transport in the outof-plane direction before being collected by the electrodes. Moreover, Fig. 1c and d also indicate that GBL SVPA can improve the perovskite filling on mesoporous $\mathrm{TiO}_{2}$ layer and that most unfilled interspaces disappeared after GBL SVPA, which will enhance charge transport and the performance of mesoporous PSCs. ${ }^{48}$

The XRD patterns are shown in Fig. 3. The XRD results indicate that they exhibit a tetragonal crystal structure. Peaks at $14.2^{\circ}, 20.1^{\circ}, 23.5^{\circ}, 24.5^{\circ}, 28.5^{\circ}$ and $31.9^{\circ}$ are diffracted by the (110), (020), (211), (202), (001), and (310) planes of $\mathrm{CH}_{3} \mathrm{NH}_{3} \mathrm{PbI}_{3}$, respectively. The peak at $26.6^{\circ}$ is the diffraction of FTO. For the films after exposure to GBL vapor annealing, the two main peaks located at $14.2^{\circ}$ and $28.5^{\circ}$ - indexed to the (110) and (220) planes-became stronger. The stronger and sharper diffraction peaks of films annealed in solvent vapor certify the improved 


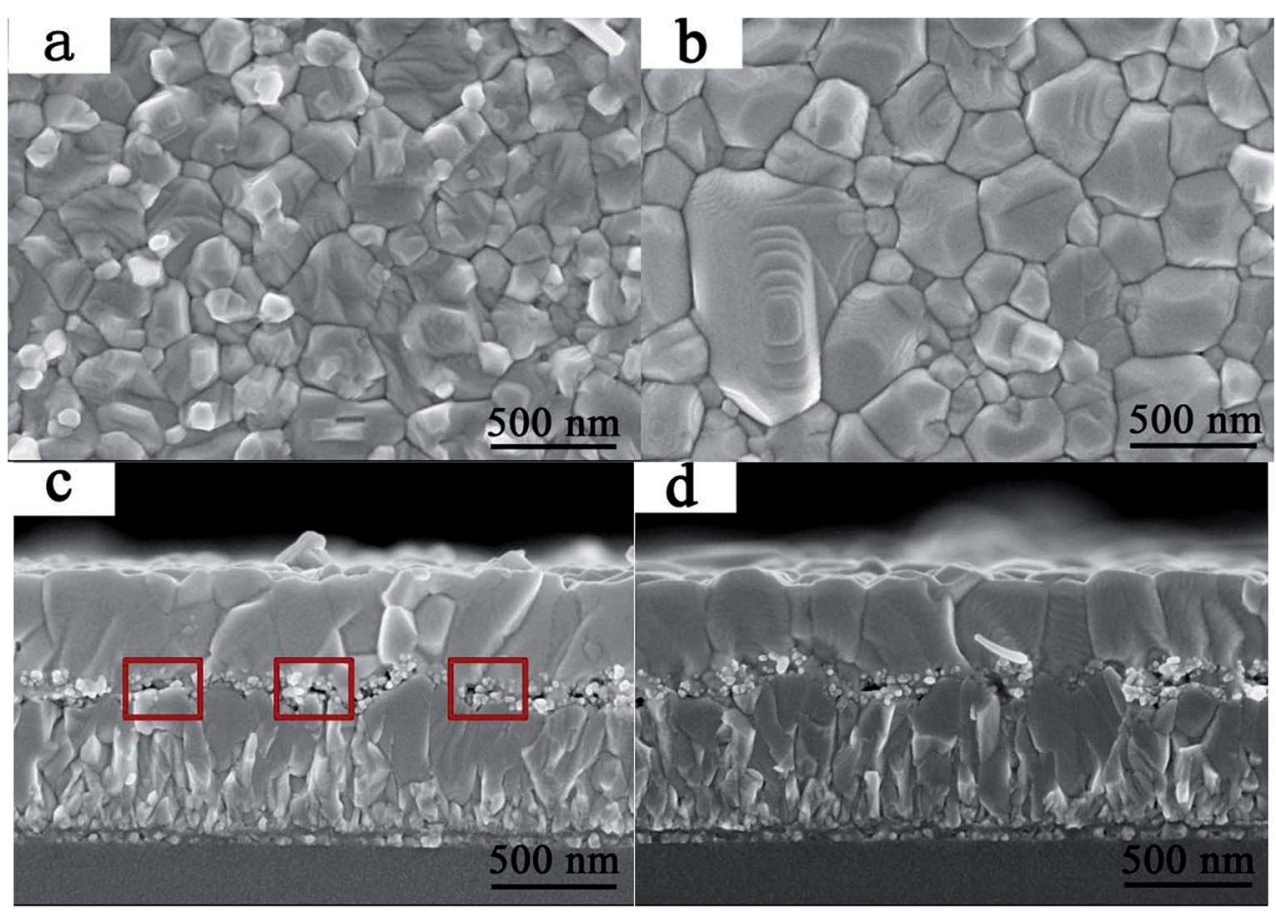

Fig. 1 Top-view and cross-section SEM images of perovskite layers (a), (c) without GBL SVPA, and (b), (d) with GBL SVPA.
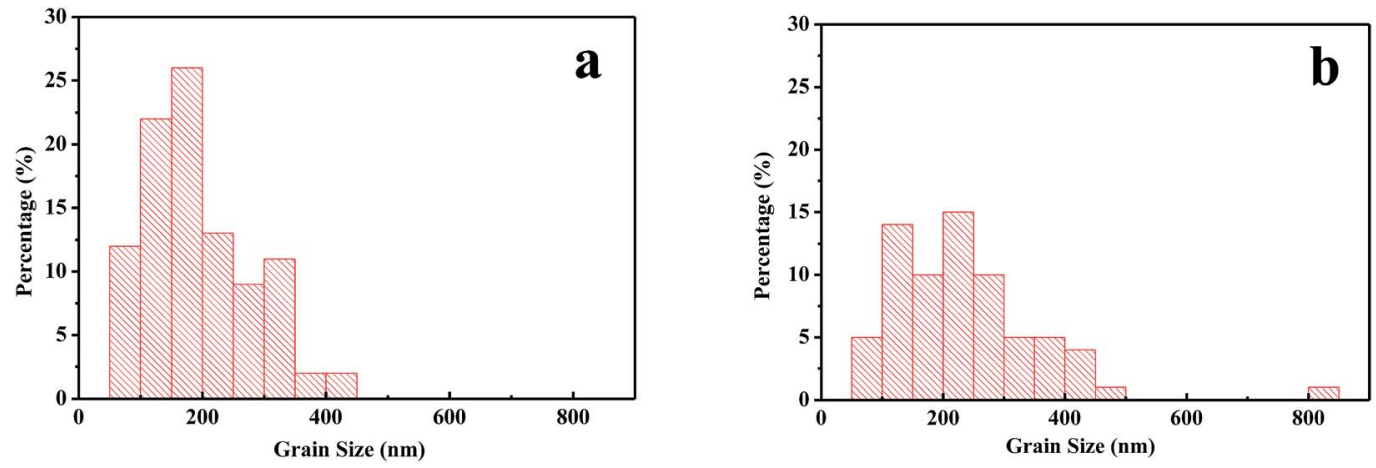

Fig. 2 Grain size distributions of perovskite layers (a) without GBL SVPA (b) with GBL SVPA.

crystallinity of the perovskite films annealed in GBL vapor. In addition, for the film without GBL SVPA a peak at $12.7^{\circ}$ related to $\mathrm{PbI}_{2}$ (001) is also observed, which indicates the presence of residual $\mathrm{PbI}_{2}$. The results also indicate that $\mathrm{PbI}_{2}$ is not completely transformed to $\mathrm{CH}_{3} \mathrm{NH}_{3} \mathrm{PbI}_{3}$ without GBL SVPA. It has been shown that the outer $\mathrm{CH}_{3} \mathrm{NH}_{3} \mathrm{PbI}_{3}$ layer insulates $\mathrm{PbI}_{2}$ from contact with the MAI solution and $\mathrm{PbI}_{2}$ remains in the films without SVPA. ${ }^{21,49}$ After GBL SVPA, no $\mathrm{PbI}_{2}$ was detected and the diffraction intensity obviously increased. That could explain how GBL SVPA enhanced the transformation of $\mathrm{PbI}_{2}$ and induced the strong recrystallization of $\mathrm{CH}_{3} \mathrm{NH}_{3} \mathrm{PbI}_{3}$. On the basis of the detailed investigation of the microstructures and $\mathrm{XRD}$ results of perovskite films, the effect and mechanism of GBL SVPA on the perovskite films were unveiled. A model (shown schematically in Scheme 2) is proposed. The low surface tension of GBL can wet perovskite well. According to the Kelvin equation (eqn (1)), the saturated vapor pressure decreases with

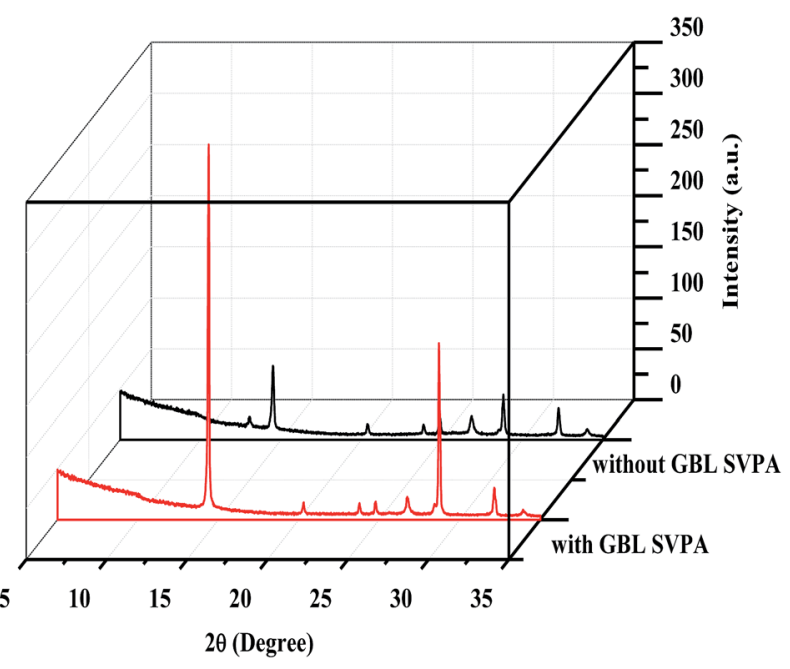

Fig. 3 XRD patterns of perovskite layers. 


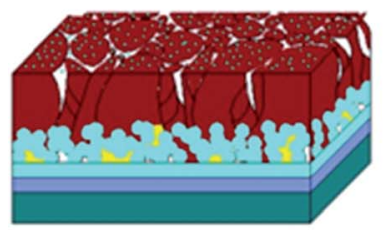

FTO

$\mathrm{TiO}_{2}$

$\mathrm{PbI}_{2}$
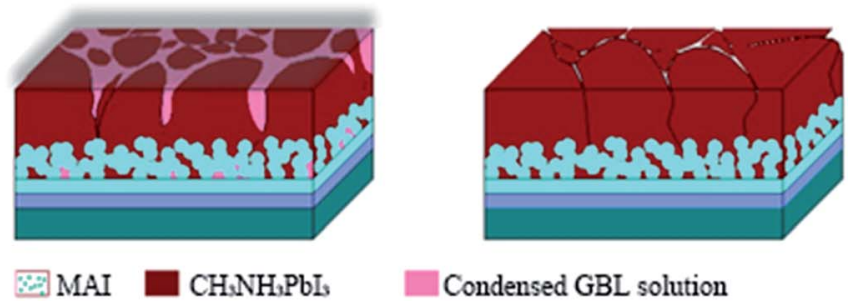

Condensed GBL solution

Scheme 2 The mechanism of GBL SVPA on the perovskite films.
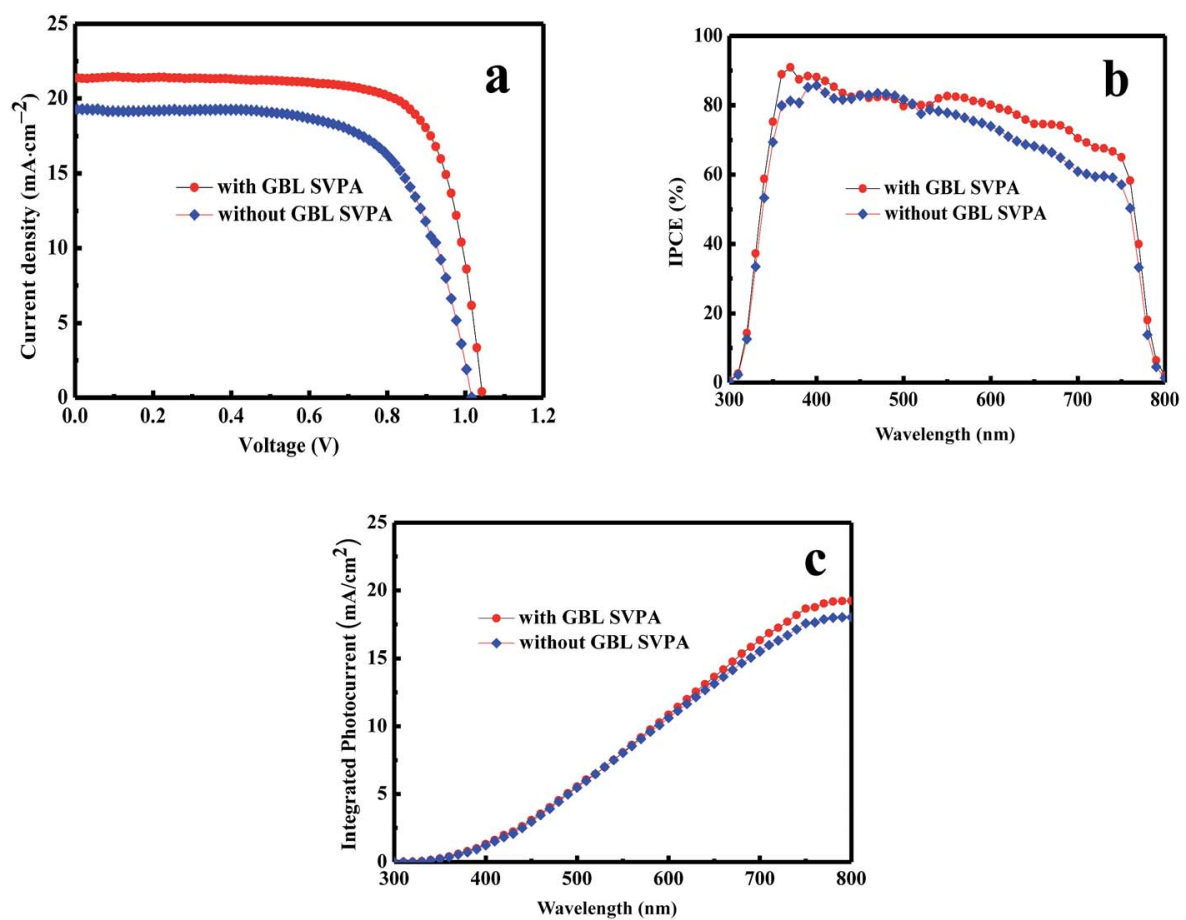

Fig. $4 J-V$, IPCE and integrated photocurrent curves of devices.

the shrinking radius of the capillary and the liquid state solvent can easily condense in the capillary. The micro-cracks between grains and pinholes in the perovskite films act like capillaries; thus, liquid solvent can condense in microcracks or pinholes even when the vapor pressure of solvent is lower than the saturated vapor pressure. Once the grain boundary of the films is filled with GBL, perovskite can be easily dissolved in the polar GBL solvent. The solubility of the solid particle can be explained using eqn (2). According to this equation, the solubility increases with decrease in particle size; therefore, the small grains dissolve first. The atoms enter the liquid phase across the liquid-solid interface and then recrystallize in areas of larger grains with lower chemical potential, which leads to an increase in grain size and crystalline quality of the grains.

In this study, perovskite layers were spin-coated instead of washing with isopropanol after dipping in MAI solution for $10 \mathrm{~min}$. Hence, there is residual MAI at the grain boundaries or on the surface. GBL solvent can also dissolve the residual MAI, then diffuse to the depth of perovskite films and react with the residual $\mathrm{PbI}_{2}$. The residual $\mathrm{PbI}_{2}$ would lead to decreased light absorption, photo-current generation, and increased charge accumulation. ${ }^{50}$ Volume expansion derived from the reaction of the residual $\mathrm{PbI}_{2}$ and MAI would fill the pores in the mesoporous layer, decreasing the porosity of the mesoporous layer, which is consistent with the SEM result.

$$
P=P_{0} \mathrm{e}^{-\frac{2 \gamma M}{\rho R T} \frac{1}{r}}
$$

$P$ : saturated vapor pressure of liquid in the wettable capillary, $P_{0}$ : saturated vapor pressure of planar liquid, $\gamma$ : surface tension of liquid, $M$ : relative molecular mass of liquid, $\rho$ : density of liquid, $R$ : gas constant, $T$ : absolute temperature, and $r$ : radius of capillary.

Table 1 Photovoltaic parameters of PSCs

\begin{tabular}{lllll}
\hline Sample & $V_{\mathrm{oc}}(\mathrm{V})$ & $J_{\mathrm{sc}}\left(\mathrm{mA} \mathrm{cm}^{-2}\right)$ & $\mathrm{FF}(\%)$ & PCE $(\%)$ \\
\hline With GBL SVPA & 1.04 & 21.30 & 0.75 & 16.58 \\
Without GBL SVPA & 1.01 & 19.30 & 0.67 & 13.05
\end{tabular}


Table 2 The performance of PSCs fabricated at different condition

\begin{tabular}{lllll}
\hline GBL solvent/SVPA time & $V_{\text {oc }}(\mathrm{V})$ & $J_{\text {sc }}\left(\mathrm{mA} \mathrm{cm}^{-2}\right)$ & FF $(\%)$ & PCE $(\%)$ \\
\hline $0 \mu \mathrm{L} / 30 \mathrm{~min}$ & 1.01 & 19.30 & 0.67 & 13.05 \\
$5 \mu \mathrm{L} / 30 \mathrm{~min}$ & 1.02 & 20.15 & 0.73 & 15.06 \\
$10 \mu \mathrm{L} / 30 \mathrm{~min}$ & 1.04 & 21.30 & 0.75 & 16.58 \\
$20 \mu \mathrm{L} / 30 \mathrm{~min}$ & 0.99 & 21.11 & 0.71 & 14.99 \\
$10 \mu \mathrm{L} / 10 \mathrm{~min}$ & 1.01 & 20.77 & 0.71 & 14.92 \\
$10 \mu \mathrm{L} / 20 \mathrm{~min}$ & 1.03 & 21.00 & 0.73 & 15.78 \\
$10 \mu \mathrm{L} / 30 \mathrm{~min}$ & 1.04 & 21.30 & 0.75 & 16.58 \\
$10 \mu \mathrm{L} / 60 \mathrm{~min}$ & 1.00 & 20.88 & 0.71 & 14.91
\end{tabular}

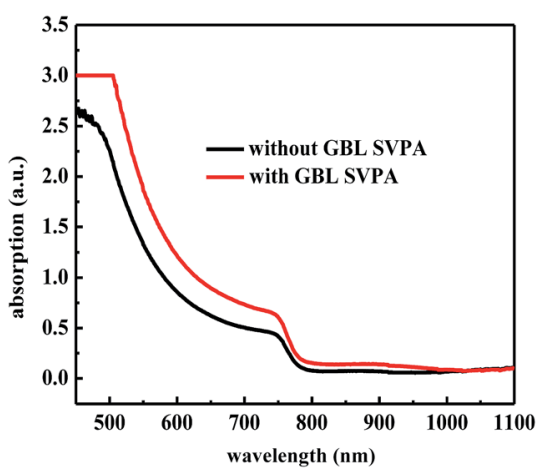

Fig. 5 UV-vis absorption spectra of perovskite layers.

$$
C=C_{0} \mathrm{e}^{\frac{2 \gamma_{\mathrm{sl}} M}{\rho R T} \frac{1}{r}}
$$

$C$ : solubility of small particle, $C_{0}$ : solubility of bulk solid, $\rho$ : density of solid, $\gamma_{\mathrm{sl}}$ : tension of liquid-solid interface, $M$ : relative molecular mass of solid, $R$ : gas constant, $T$ : absolute temperature, $r$ : radius of small particle.

\section{Solar cell performance}

PSCs were fabricated to probe the effect of GBL SVPA on device performance. Fig. 4 contains the current density-voltage $(J-V)$ and IPCE curves of the solar cell. The detailed photovoltaic parameters are summarized in Table 1. As expected, the GBL SVPA devices displayed better performance than those without GBL SVPA. The short circuit current density $\left(J_{\mathrm{sc}}\right)$, open circuit voltage $\left(V_{\mathrm{oc}}\right)$, fill factor (FF), and PCE of the device after GBL SVPA were higher than those of the device without GBL SVPA. $J_{\mathrm{sc}}$ increased from $19.3 \mathrm{~mA} \mathrm{~cm}^{-2}$ for the device without GBL SVPA to $21.3 \mathrm{~mA} \mathrm{~cm}^{-2}$ for the device with GBL SVPA. The PCE of the device with GBL SVPA reached $16.58 \%$, which was $27.05 \%$ larger than the value of the device without GBL SVPA. The obviously improved $V_{\text {oc }}$ from $1.01 \mathrm{~V}$ (device without GBL SVPA) to $1.04 \mathrm{~V}$ (device with GBL SVPA) means that the potential loss in the device is reduced. The $V_{\mathrm{oc}}$ in a photovoltaic device is determined by the quasi-Fermi level splitting of electrons and holes in the whole device under illumination, which is mainly affected by the occupation of available electronic states by photo-generated charge carriers in the perovskite layer. If there are many defects and recombination centers induced by structural and chemical disorder such as low crystallinity, grain boundaries, and random orientations, the occupation of the available electronic states in the perovskite layer will change, which can reduce the quasi-Fermi level splitting value. Thus, there will be a relatively small $V_{\text {oc }}$. Since all devices were fabricated by the same procedure except for the perovskite layer annealing condition, the differences in $V_{\text {oc }}$ between the devices should reflect the quality of the perovskite layer. A larger $V_{\mathrm{oc}}$ should result from a better perovskite quality.

The amounts of GBL solvent and SVPA time were varied in the preparation of perovskite film in our experiment. The results are summarized in Table 2 . All devices were fabricated by
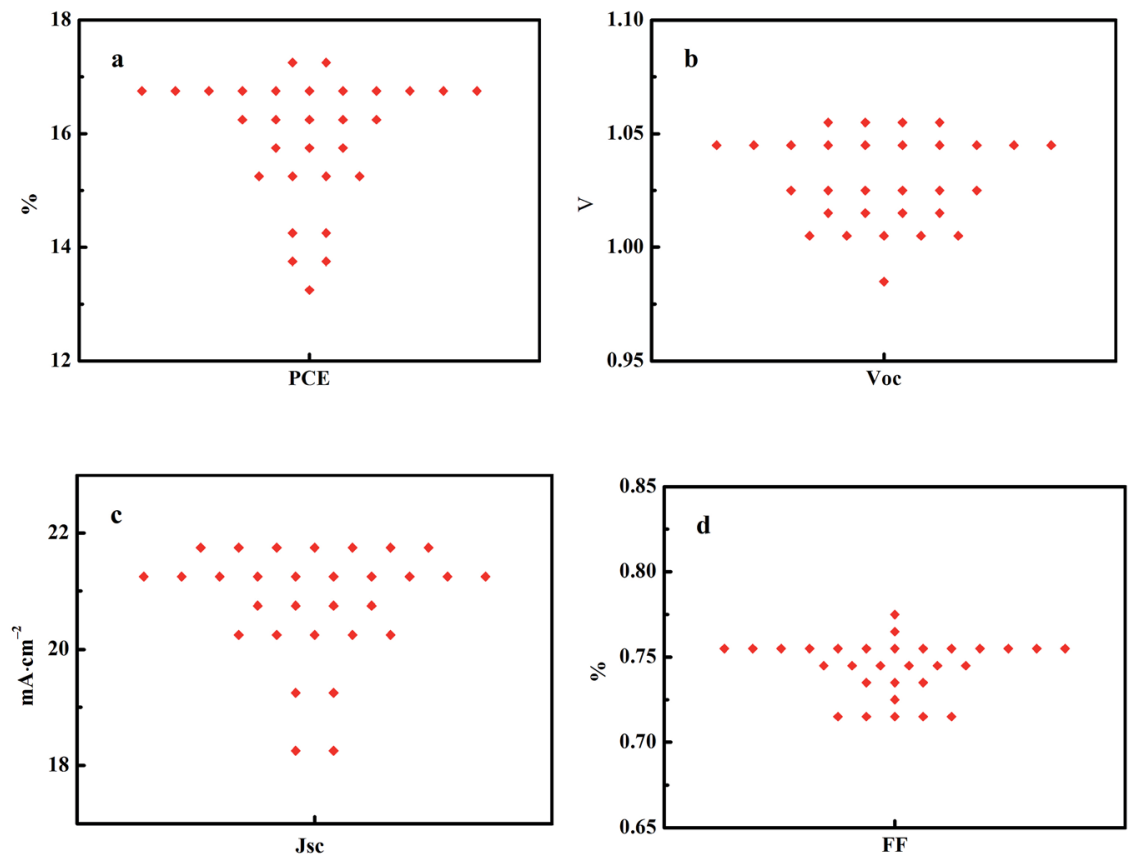

Fig. 6 Statistics distribution chart of the performance of PSCs with GBL SVPA. 


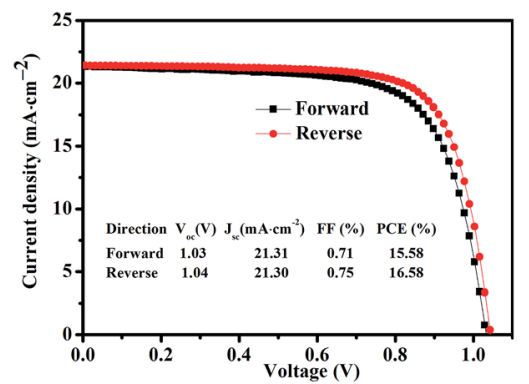

Fig. 7 The performance of PSCs with GBL SVPA in both forward and reversed sweeping

the same procedure except for the variable amounts of GBL solvent and SVPA time in the preparation of perovskite film. We found that the device achieved best efficiency when the SVPA time was $30 \mathrm{~min}$ and the GBL solvent was $10 \mu \mathrm{L}$.

The performance improvement of the device can be attributed to the following two reasons. First is that the device with GBL SVPA has larger grain sizes and better crystal quality, which are expected to reduce the overall bulk defect density and hence suppress charge trapping and exciton recombination. The second is due to the complete reaction of $\mathrm{PbI}_{2}$ with MAI, which increases the amount of light absorbing perovskite material. The UV-vis absorption spectra of the perovskite layers were also measured (Fig. 5). Fig. $4 \mathrm{~b}$ also shows representative IPCE curves for the devices. The curves begin to increase rapidly around $350 \mathrm{~nm}$, which is related to the high optical absorption of the perovskite absorber. A higher IPCE was observed for the GBL SVPA device. The slightly higher IPCE of the GBL SVPA device from $400 \mathrm{~nm}$ to $700 \mathrm{~nm}$ is in agreement with the increase of $J_{\mathrm{sc}}$ associated with these devices. $J_{\mathrm{sc}}$ is calculated by integrating the IPCE spectrum based on eqn (3). ${ }^{50}$ The calculated current densities are $19.23 \mathrm{~mA} \mathrm{~cm}{ }^{-2}$ and $18.01 \mathrm{~mA} \mathrm{~cm}^{-2}$ for the devices with and without GBL SVPA, respectively, which are close to the measured $J_{\mathrm{sc}}$ values.

$$
J_{\mathrm{sc}}=q \int \operatorname{IPCE}(\lambda) \phi_{\mathrm{AM} 1.5}(\lambda) \mathrm{d} \lambda
$$

$J_{\text {sc: }}$ short circuit current, $q$ : quantity of electric charge, IPCE $(\lambda)$ : the obtained IPCE profile as a function of wavelength $(\lambda)$, and AM1.5 $(\lambda)$ : the solar spectral irradiance at a specific wavelength $(\lambda)$.

Fig. 6 shows statistics distribution charts of the performance of PSCs. As reflected in Fig. 6, the average $V_{\mathrm{oc}}, J_{\mathrm{sc}}$, FF and PCE were $1.03 \pm 0.2 \mathrm{~V}, 20.76 \pm 0.92 \mathrm{~mA} \mathrm{~cm}^{-2}, 0.74 \pm 0.02$, and 15.93 $\pm 1.06 \%$ respectively. 30 cells were measured in total. Fig. 7 presents the performance of PSCs in both forward and reversed sweeping. As can be seen from Fig. 7, the reverse sweeping of the device has a slight advantage in the efficiency and fill factor.

\section{Conclusions}

GBL SVPA was introduced to fabricate high quality $\mathrm{CH}_{3} \mathrm{NH}_{3} \mathrm{PbI}_{3}$ perovskite films. We have studied the effect of GBL SVPA on the microstructure and crystal quality of the grains of the perovskite layer and the photovoltaic performance of devices. A theoretical mechanism of GBL SVPA was also proposed based on the chemical physics of surfaces. After GBL SVPA at $75{ }^{\circ} \mathrm{C}$, the corresponding perovskite layers had larger grain sizes, better crystal quality of the grains, and no detected residual $\mathrm{PbI}_{2}$. The energy loss in PCSs is derived from the non-radiative recombination of charges due to trap states on film surfaces, at grain boundaries, and at point defects (such as vacancies or interstitial defects) in the perovskite crystal lattice. Perovskite films with large crystallites and grain size would effectively remove these points, suppress energetic disorders, and enable improved performance of perovskite photovoltaic devices. The highest PCE of $16.58 \%$ was achieved when illuminated and tested under standard AM1.5 conditions.

\section{Conflicts of interest}

There are no conflicts to declare.

\section{Acknowledgements}

Parts of this work were supported by the International Science \& Technology Cooperation Program of China (No. 2013DFA51000), the National Natural Science Foundation of China (No. 51462015 and 51403090), and the International Science \& Technology Cooperation Program of Jiangxi Province (No. 20122BDH80003).

\section{Notes and references}

1 K. Wojciechowski, M. Saliba, T. Leijtens, A. Abate and H. J. Snaith, Energy Environ. Sci., 2013, 7, 1142-1147.

2 J. Burschka, N. Pellet, S. J. Moon, R. Humphry-Baker, P. Gao, M. K. Nazeeruddin and M. Grätzel, Nature, 2013, 499, 316340.

3 S. D. Wolf, J. Holovsky, S. J. Moon, P. Löper, B. Niesen, M. Ledinsky, F. J. Haug, J. H. Yum and C. Ballif, J. Phys. Chem. Lett., 2014, 5, 1035-1039.

4 V. D'Innocenzo, G. Grancini, M. J. P. Alcocer, A. R. S. Kandada, S. D. Stranks, M. M. Lee, G. Lanzani, H. J. Snaith and A. Petrozza, Nat. Commun., 2014, 5, 3586.

5 A. Miyata, A. Mitioglu, P. Plochocka, O. Portugall, J. T. W. Wang, S. D. Stranks, H. J. Snaith and R. J. Nicholas, Nat. Phys., 2015, 11, 582-587.

6 S. D. Stranks, G. E. Eperon, G. Grancini, C. Menelaou, M. J. P. Alcocer, T. Leijtens, L. M. Herz, A. Petrozza and H. J. Snaith, Science, 2013, 342, 341-344.

7 L. Y. Yang, A. T. Barrows, D. G. Lidzey and T. Wang, Rep. Prog. Phys., 2016, 79, 026501.

8 A. Kojima, K. Teshima, Y. Hirai and T. Miyasak, J. Am. Ceram. Soc., 2009, 131, 6050-6051.

9 M. Saliba, T. Matsui, J. Y. Seo, K. Domanski, J. P. CorreaBaena, M. K. Nazeeruddin, S. M. Zakeeruddin, W. Tress, A. Abate, A. Hagfeldt and M. Grätzel, Energy Environ. Sci., 2016, 9, 1989-1997.

10 J. H. Im, I. H. Jang, N. Pellet, M. Grätzel and N. G. Park, Nat. Nanotechnol., 2014, 9, 927-932.

11 Q. F. Dong, Y. J. Fang, Y. C. Shao, P. Mulligan, J. Qiu, L. Cao and J. S. Huang, Science, 2015, 347, 967-970. 
12 W. Y. Nie, H. H. Tsai, R. Asadpour, J. C. Blancon, A. J. Neukirch, G. Gupta, J. J. Crochet, M. Chhowalla, S. Tretiak, M. A. Alam, H. L. Wang and A. D. Mohite, Science, 2015, 347, 522-525.

13 Z. G. Xiao, Q. F. Dong, C. Bi, Y. C. Shao, Y. B. Yuan and J. S. Huang, Adv. Mater., 2014, 26, 6503-6509.

14 N. J. Jeon, J. H. Noh, Y. C. Kim, W. S. Yang, S. Ryu and S. Seok, Nat. Mater., 2014, 13, 897-903.

15 T. Y. Zhang, M. J. Yang, Y. X. Zhao and K. Zhu, Nano Lett., 2015, 15, 3959-3963.

16 P. Fan, D. Gu, G. X. Liang, J. T. Luo, J. L. Chen, Z. H. Zheng and D. P. Zhang, Sci. Rep., 2016, 6, 29910.

17 N. Ahn, D. Y. Son, I. H. Jang, S. M. Kang, M. Choi and N. G. Park, J. Am. Chem. Soc., 2015, 137, 8696-8699.

18 M. J. Yang, Y. Y. Zhou, Y. Zeng, C. S. Jiang, N. P. Padture and K. Zhu, Adv. Mater., 2015, 27, 6363-6370.

19 H. Ebe and H. Araki, Jpn. J. Appl. Phys., 2016, 55, $02 \mathrm{BF} 11$.

20 C. T. Zuo and L. M. Ding, Nanoscale, 2014, 6, 9935-9938.

21 T. Y. Zhang, M. J. Yang, Y. X. Zhao and K. Zhu, Nano Lett., 2015, 15, 3959-3963.

22 S. T. Bag and M. F. Durstock, ACS Appl. Mater. Interfaces, 2016, 8, 5053-5057.

23 Q. J. Liang, J. G. Liu, Z. K. Cheng, Y. Li, L. Chen, R. Zhang, J. D. Zhang and Y. C. Han, J. Mater. Chem. A, 2016, 4, 223-232.

24 G. R. Perumallapelli, S. R. Vasa and J. Jang, Org. Electron., 2016, 31, 142-148.

25 L. J. Zuo, S. Q. Dong, N. D. Marco, Y. T. Hsieh, S. H. Bae, P. Y. Sun and Y. Yang, J. Am. Chem. Soc., 2016, 138, 15710-15716.

26 Q. Y. Xu, D. X. Yuan, H. R. Mu, F. Igbari and Q. L. Bao, Nanoscale Res. Lett., 2016, 11, 248.

27 W. Q. Wu, D. Chen, F. Huang, Y. B. Cheng and R. A. Caruso, J. Mater. Chem. A, 2016, 4, 12463-12470.

28 M. I. El-Henawey, R. S. Gebhardt, M. M. El-Tonsya and S. Chaudhary, J. Mater. Chem. A, 2016, 4, 1947-1952.

29 Y. F. Wang, S. B. Li, P. Zhang, D. T. Liu, X. L. Gu, H. Sarvari, Z. B. Ye, J. Wu, Z. M. Wang and Z. D. Chen, Nanoscale, 2016, 8, 19654-19661.

30 Z. G. Zhou, L. M. Huang, X. F. Mei, Y. Zhao, Z. H. Lin, H. Y. Zhen and Q. D. Ling, Sol. Energy, 2016, 136, 210-216.

31 F. Huang, W. C. Huang, Y. M. Dkhissi, Y. Zhu, J. Etheridge, A. Gray-Weale, U. Bach, Y. B. Cheng and L. Spiccia, Angew. Chem., Int. Ed. Engl., 2014, 53, 9898-9903.

32 J. Liu, C. Gao, X. L. He, Q. Y. Ye, L. Q. Ouyang, D. Zhuang, C. Liao, J. Mei and W. Lau, ACS Appl. Mater. Interfaces, 2015, 7, 24008-24015.
33 Z. G. Xiao, Q. F. Dong, C. Bi, Y. C. Shao, Y. B. Yuan and J. S. Huang, Adv. Mater., 2014, 26, 6503-6509.

34 S. S. Dinachali, W. B. Bai, K. H. Tu, H. K. Choi, J. S. Zhang, M. E. Kreider, L. C. Cheng and C. A. Ross, ACS Macro Lett., 2015, 4, 500-504.

35 G. Li, V. Shrotriya, J. S. Huang, Y. Yao, T. Moriarty, K. Emery and Y. Yang, Nat. Mater., 2005, 4, 864-868.

36 B. Li, T. G. Jiu, C. Y. Kuang, S. H. Ma, Q. S. Chen, X. D. Li and J. F. Fang, Org. Electron., 2016, 34, 97-103.

37 J. D. Wang, X. Xiang, X. Yao, W. J. Xiao, J. Lin and W. Shi, Org. Electron., 2016, 39, 1-9.

38 B. B. Wang, Z. G. Zhang, S. Y. Ye, H. X. Rao, Z. Q. Bian, C. H. Huang and Y. F. Li, J. Mater. Chem. A, 2016, 4, 17267-17273.

39 C. Liu, K. Wang, C. Yi, X. J. Shi, A. W. Smith, X. Gong and A. J. Heeger, Adv. Funct. Mater., 2016, 26, 101-110.

40 L. Z. Zhu, B. Yuh, S. Schoen, X. P. Li, M. Aldighaithir, B. J. Richardson, A. Alamera and Q. M. Yu, Nanoscale, 2016, 8, 7621-7630.

41 F. Zhang, J. Song, L. X. Zhang, F. F. Niu, Y. Y. Hao, P. G. Zeng, H. B. Niu, J. S. Huang and J. R. Lian, J. Mater. Chem. A, 2016, 4, 8554-8561.

42 X. Sun, C. F. Zhang, J. J. Chang, H. F. Yang, H. Xi, G. Lu, D. Z. Chen, Z. H. Lin, X. L. Lu, J. C. Zhang and Y. Hao, Nano Energy, 2016, 28, 417-425.

43 J. Chen, T. F. Shi, X. H. Li, B. K. Zhou and H. X. Cao, Appl. Phys. Lett., 2016, 108, 053302.

44 Q. Q. Ge, J. Ding, J. Liu, J. Y. Ma, Y. X. Chen, X. X. Gao, L. J. Wan and J. S. Hu, J. Mater. Chem. A, 2016, 4, 1345813467.

45 H. Yu, X. D. Liu, Y. J. Xia, Q. Q. Dong, K. C. Zhang, Z. W. Wang, Y. Zhou, B. Song and Y. F. Li, J. Mater. Chem. A, 2016, 4, 321-326.

46 W. S. Yang, J. H. Noh, N. J. Jeon, Y. C. Kim, S. Ryu, J. Seo and S. Seok, Science, 2015, 348, 1234-1237.

47 M. I. Saidaminov, A. L. Abdelhady, B. Murali, E. Alarouse, V. M. Burlakov, W. Peng, I. Dursun, L. F. Wang, Y. He, G. Maculan, A. Goriely, T. Wu, O. F. Mohammed and O. M. Bakr, Nat. Commun., 2015, 6, 7586.

48 T. Leijtens, B. Lauber, G. E. Eperon, S. D. Stranks and H. J. Snaith, J. Phys. Chem. Lett., 2014, 5, 1096-1102.

49 C. Y. Jiang, S. L. Lim, W. P. Goh, F. X. Wei and J. Zhang, ACS Appl. Mater. Interfaces, 2015, 7, 24726-24732.

50 S. Ma, M. W. Shang, L. Y. Yu and L. F. Dong, J. Mater. Chem. A, 2015, 3, 1222-1229. 